la idea de tiempo malgastado, a menudo con cierto cariz de reproche y burla. Al dar forma latinizada a la frase popular se aumenta el tono humorístico. ${ }^{3}$

La locución debió nacer entre gente de iglesia o allegada, que bromearia remodelando la locución romance ires y venires, sobre las tan familiares palabras litúrgicas paralelas ite y venite.

Arlington, Massachusetts.

PEDRO GRASES.

\title{
TRES NOTAS AL "QUIJOTE"
}

En el capítulo xxiII de la primera parte del 2uijote (De lo que le aconteció al famoso don 2uijote en Sierra Morena) escribe Cervantes:

En esto [Sancho] alzó los ojos y vió que su amo estaba parado procurando con la punta del lanzón alzar no sé qué bulto que estaba caído en el suelo, por lo cual se dió priesa a llegar a ayudarle, si fuese menester; y cuando llegó fué a tiempo que alzaba con la punta del lanzón un cojín y una maleta asida a él.

\section{Rodríguez Marín anota :}

ni el Tesoro de Covarrubias ni ningún otro de los léxicos que tengo a mano da de la voz cojín acepción que convenga enteramente a este lugar del texto. Debía de ser como una doble bolsa de tela gruesa, a juzgar por estos versos de un romance de Góngora (Romancero general, fol. 403 vto.):

Sacó poquito a poco

de las bolsas de un coxín

dos varicas de virtudes de traça y valor sutil.

En parte tiene razón Rodríguez Marín, pues parece que manga y cojín eran sinónimos, según lo demuestra Gabriel de Corral, La Cintia de Aranjuez, Madrid, 1629, reeditada por Joaquín de Entrambasaguas, Biblioteca de antiguos libros hispánicos, IV, Madrid, 1945, pág. 77:

Hizieron juizio las dos de que el coxín que auía traído el día antes Perecindo sería sin duda deste Cauallero.

Al relatar el hallazgo del cojín dice Perecindo (pág. 38) :

Bueluo la cabeça y veo vn rozín, pared en medio de cauallo, que traía casi colgados estos adereços; quise cogerle mas al llegar me assentó, no sé como se llaman las cozes en pastoril cultura, dos destas, en fin, como para mí. Con la fuerça acabaron de desasirse estos ajuares y el rozín, más que de passo, se fué por esos prados adelante. Bien quisiera desbalijar esta manga, mas parecióme poca fide, lidad. 1

3 Una forma correlativa en el lenguaje literario "con acumulación de palabras que suenan a latín" es la empleada por Fr. Antonio de Guevara: ". . . sus cortesanos lo pasan de theatros en theatros, de flámines en flámines, de ludos en ludos, de plazas en plazas, de termas en termas, de nugibundos en nugibundos" (cita de M. R. Lida, RFH, VII, 1946, págs. $365-366$.)

1 Es de hacer notar que el hallazgo que hace Perecindo de la maleta que contiene ropa y unos papeles con versos se parece mucho al ocurrido en el capítulo que anoto del Quijote, donde Sancho encuentra una maleta que contiene las mismas cosas. 
En el mismo sentido parece que usa la voz cojín D. Alonso del Castillo Solórzano, La niña de los embustes. Teresa de Manzanares, Barcelona, 1632, ed. Cotarelo y Mori, Colección selecta de antiguas novelas españolas, III, Madrid, 1906, pág. 114:

Apeados que fuimos de las mulas, quitaron dellas los cojinetes y portamanteos, sin osar nadie replicar a la voluntad de aquellos ladrones . . . Así los dejaron atados cada uno a un roble, y cargando con la ropa y cojines, dieron con ellos y conmigo en otra estancia más oculta.

\title{
II
}

En el capítulo xII de la segunda parte (De la extraña aventura que le sucedió al valeroso don 2 uijote con el bravo Caballero de los Espejos) dice Cervantes:

Habiendo entreoído el Caballero del Bosque que hablaban cerca dél, sin pasar adelante en su lamentación, se puso en pie, y dijo con voz sonora y comedida: “¿Quién va allá? ¿Qué gente? ¿Es por ventura de la del número de los contentos, o de los afligidos?"

Casi idénticas palabras encontramos en los versos 95-97 de la égloga de Garcilaso:

\author{
Llegarme quiero cerca con buen tiento \\ y ver, si de mí fuere conocido, \\ si es del número triste o del contento. ${ }^{2}$
}

Ya se sabe que Garcilaso era el poeta castellano por antonomasia. Las muchas ediciones de sus poesías, principalmente las del Brocense, Fernando de Herrera y D. Tomás Tamayo de Vargas, habían hecho que sus versos se llegaran a saber de coro. ${ }^{3}$ En torno a la propiedad de estas anotaciones gira la ruidosa polémica entre Fernando de Herrera y el Prete Jacopín (D. Juan Fernández de Velasco). Sebastián de Córdoba se encarga de tornar "a lo divino" las obras del poeta toledano y D. Juan de Andosilla Larramendi de hacer centones con sus versos. Con estos antecedentes no nos puede extrañar que a la vista de las "tobosescas tinajas" D. Quijote largue redondos los primeros versos del soneto X de Garcilaso (2uijote, segunda parte, capítulo XVIII). ${ }^{4}$

Se pone así en evidencia que las palabras del Caballero del Bosque, o sea el ladino bachiller Sansón Carrasco, no son una reminiscencia casual. Cervantes escribe a propósito esas líneas para regalar el oído de los lectores y traerles a la memoria el cuadro del enamorado pastor Albanio entregado a sus quejas amorosas, situación tan semejante a la del Caballero del Bosque.

\section{III}

En el capítulo xxvir de la segunda parte del 2uijote (Donde se da cuenta quiénes eran Maese Pedro y su mono) dice el hidalgo manchego:

2 Alguna reminiscencia más imprecisa anota Navarro Tomás a la pág. 127, nota 2, de su edición de las poesías de Garcilaso para los Clásicos Castellanos.

3 Se puede tener una noción de la fama de Garcilaso consultando la obra de Guillermo Díaz-Plaja, Garcilaso y la poesía española (1536-1936), Seminario de estudios hispánicos, volumen II, Barcelona, 1937.

4 Recoge testimonios de la fama de este soneto Miguel Herrero-García, Estima. ciones literarias del siglo XvI, Madrid, 1930, págs. 79-89. Algunas citas no recogidas por Herrero-García se pueden ver en el artículo de J. M. Alda Tesán, Fortuna de un verso garcilasiano, RFE, 1943, xxvis, págs. $77-82$. 
¡Bueno sería que se matasen a cada paso los del pueblo de la Reloja con quien se lo llama, ni los cazoleros, berenjeneros, ballenatos, jaboneros, ni los de otros nombres y apellidos que andan por ahí en boca de los muchachos y, de gente de poco más a menos!

La crítica ha llegado a establecer que estos remoquetes se aplicaban a los siguientes pueblos: pueblo de la Reloja a Espartinas, ${ }^{5}$ cazoleros a los de Valladolid, berenjeneros a los de Toledo, ${ }^{6}$ ballenatos a los de Madrid. El apelativo de jaboneros no se sabía si se aplicaba a los de Ocaña o a los de Getafe.

La primera en dilucidar quiénes serían los tales jaboneros fué doña María Goyri de Menéndez Pidal, Dos notas para el "Quijote", RFE, 1915, II, págs. 33-40, donde demostró, por una cita del Cancionero de Herberay des Essarts y dos pasajes de las Décadas de Alonso de Palencia, que recibían tal nombre los sevillanos. Un poco más adelantó Rodríguez Marín aduciendo un pasaje de la Historia de Sevilla (1587) de Alonso de Morgado.

He encontrado dos nuevos textos que acaban de explicarnos la razón de tal denominación. El primero es un pasaje del Libro de las grandezas y cosas memorables de España, Sevilla, 1548, del tratadista de cosmografía y de náutica Pedro de Medina.7 En el capítulo XLV, De la población que se llama Triana, guarda y collación de Sevilla, y cosas señaladas que en ella ha habido y hay, dice lo siguiente (pág. 76):

Aquí en Triana es una casa notable, tal que por ella se paga de renta en cada un año siete mil ducados. En esta casa se hace el xabón blanco con que se provee gran parte de Castilla, Indias, Inglaterra, Flandes y otras parte. Hácense ordinariamente en esta casa en cada un año más de quince mil quintales de xabón, de lo blanco, donde cada año se gastan de aceite con que este jabón se hace más de cincuenta mil arrobas; de los otros materiales, cal, leña y ceniza, no se puede contar; es muy grande el aderezo que en esta casa hay con que este xabón se hace; especialmente trece calderas que en cada una cabe más de a doscientas arrobas, donde junto el aceite y lejía, cuando hierve, levanta con el fuego muy grandes borbollones a maravilla. Aquí andan a la contina casi cuarenta hombres labrando y haciendo este xabón.

El segundo texto proviene de la Miscelánea de D. Luis Zapata, ed. Pascual de Gayangos, Memorial Histórico Español, tomo XI, Madrid, 1859, en el capítulo intitulado De la mudanza de los tiempos en la variedad de los precios de las cosas (pág. 293):

El almona de Sevilla, que pienso que en arábigo quiere decir zabonería, que es el estanco de hacer xabón en Sevilla y su tierra, fué del condestable Don Rui López de Ávalos, y rentaba entonces ciento y sesenta mil maravedís toda ella. Repartióse por bienes de aquel noble y gran caballero, que "allá van leyes do quieren reyes" y es la misma que hoy poseemos tres personas: el duque de Alcalá, el marqués de Villamanrique y yo, que lo que rentaba en tiempo de nuestros avuelos los dichos ciento y sesenta mil maravedís, hoy renta veinte mil ducados y cada día sube aquesta renta. 8

5 Rodríguez Marín (ed. crítica de Rinconete y Cortadillo, Sevilla, 1905, pág. 193; Quijote, ed. Clásicos Castellanos, tomo vI, pág. 185 y ed. Madrid, 1916, tomo v, pág. 82; Ensaladilla, Madrid, 1923, pág. 66) no hace más que repetir lo ya dicho por Aureliano Fernández-Guerra acerca de la identificación del pueblo de la Reloja en $\mathrm{Al}$. gunos datos nuevos para ilustrar el "Quijote", apud Gallardo, Ensayo, tomo I, col. 1317 .

6 Cf. mi artículo Sobre Juan Alfonso de Baena, RFH, 1946, vili, págs. 143-145.

7 Cito por la reedición moderna de Ángel González Palencia, Clásicos Españoles, I, Madrid, 1944.

8 La Miscelánea se terminó de escribir en 1593, o sea que en menos de medio siglo la renta se había triplicado, de acuerdo con el dato de Pedro de Medina. 
Nos falta una obra que recoja todos estos remoquetes lugareños, reproduciendo los textos en que se basa. La obra de Martín y Gadea a que hace referencia Rodríguez Marín se circunscribe a la región valenciana. Aurelio Báig Baños pensaba publicar algunos, pero, que yo sepa, no llegó a hacerlo (vid. Rodríguez Marín anotador del "Quijote", en EIU, 1931, II, pág. 481).

JUAN BAUTISTA AVALLE ARCE.

Buenos Aires. 